\title{
Avaliação da durabilidade de concretos produzidos com agregados de resíduo de concreto utilizando a abordagem de mistura dois estágios
}

\author{
Evaluation of the durability of concretes \\ produced with recycled concrete aggregates \\ using the two stage mixing approach
}

Carla Mabel Medeiros de Albuquerque e Silva ${ }^{1}$, Valdirene Maria Silva Capuzzo ${ }^{1}$

\footnotetext{
${ }^{1}$ Programa de Pós-Graduação em Estruturas e Construção Civil - Universidade de Brasília, Campus Universitário Darcy Ribeiro, CEP 70910-900, Brasília, DF, Brasil.

e-mail: carlamabeleng@gmail.com,valdirenemaria@unb.br
}

\section{RESUMO}

A reciclagem da fração mineral de resíduos da construção civil é vista como uma potencial fonte de geração de agregados. Os Agregados de Resíduo de Concreto (ARC) são geralmente indicados para se utilizar na produção de novos concretos. No entanto, devido à argamassa antiga aderida aos ARC, estes possuem massa específica menor e maior porosidade quando comparado ao agregado natural. Na busca de melhorar a qualidade dos ARC, várias técnicas vêm sendo desenvolvidas, sendo uma das alternativas através da modificação da superfície. Este estudo objetivou verificar o efeito da substituição de $20 \%$ de agregado graúdo natural por ARC e realizar a modificação da superfície dos ARC através da abordagem de mistura dois estágios. A substituição dos agregados foi realizada mantendo a distribuição granulométrica do agregado graúdo natural. O tratamento do ARC foi realizado no período de pré-molhagem com os teores de 25 e $100 \%$ de cimento Portland. Foram realizados ensaios para avaliar o comportamento dos concretos em relação às propriedades mecânicas e parâmetros de durabilidade. Ficou evidente que a utilização de $20 \%$ de ARC na produção de um novo concreto produz efeitos negativos nas propriedades avaliadas quando comparado ao concreto convencional. O tratamento nos ARC através da abordagem de mistura dois estágios com $25 \%$ de cimento Portland proporcionou melhoria no concreto quando comparado à abordagem de mistura normal. Por outro lado, a abordagem de mistura dois estágios com $100 \%$ de cimento Portland prejudicou o comportamento do concreto. Foi concluído que a abordagem de mistura dois estágios com $25 \%$ de cimento Portland mostrou-se como uma alternativa viável para proporcionar melhorias nos ARC. Além de resultar em um concreto com boas características de propriedades mecânicas e durabilidade, também viabiliza a utilização de agregados reciclados e não gera custo adicional no processo de produção do concreto.

Palavras-chave: concreto; agregado de resíduo de concreto; abordagem de mistura dois estágios; durabilidade.

\footnotetext{
ABSTRACT

The recycling of the mineral fraction of civil construction residues is seen as a source potential of generation of aggregates. The Recycled Concrete Aggregates (RCA) are generally indicated for using in the production of new concretes. However, due to the old mortar adhered to RCA, these have smaller specific mass and higher porosity when compared to the natural aggregate. In the seek of improving the quality of RCA, various techniques have being developed, being one of the alternatives through of surface modification. This study objectified to verify the effect of the substitution of $20 \%$ of natural coarse aggregate by RCA and to perform the surface modification of the RCA through the two stage mixing approach. The replacement of aggregates was performed maintaining the particle size distribution of the natural coarse aggregate. The RCA treatment was performed in the pre-wetting period with contents of 25 and $100 \%$ of Portland cement. It were performed tests to evaluate the behavior of concretes in relation to mechanical properties and durability parameters. It was evident that the utilization of $20 \%$ of RCA in the production of a new concrete produces
} 
negative effects on the evaluated properties when compared to conventional concrete. The treatment in the RCA though the two stage mixing approach with $25 \%$ of Portland cement provided improvement in the concrete when compared to the normal mixing approach. On the other hand, the two stage mixing approach with $100 \%$ of Portland cement impaired the concrete behavior. It was concluded that the two stage mixing approach with $25 \%$ of Portland cement showed as a viable alternative to provide improvements in the RCA. Besides resulting in a concrete with good characteristics of mechanical properties and durability, it also enables the utilization of recycled aggregates and it does not generates additional cost in the process of concrete production.

Keywords: concrete; recycled concrete aggregates; two stage mixing approach; durability.

\section{INTRODUÇÃO}

A reciclagem da fração mineral de resíduos da construção civil é vista como uma potencial fonte de geração de agregados. Além de proporcionar o reaproveitamento dos resíduos, diminui a dependência de agregados naturais, o que contribui para a preservação dos recursos naturais, podendo ainda gerar economia para o processo construtivo. Desta forma, a utilização de agregados reciclados possui grande importância na economia de recursos, na proteção do meio ambiente e na realização do desenvolvimento sustentável da indústria da construção civil [1].

Os agregados reciclados podem ser classificados como agregados de resíduo de concreto (ARC), os quais são compostos na sua fração graúda por no mínimo $90 \%$ em massa de fragmentos à base de cimento Portland e rochas; e agregados de resíduo misto (ARM), os quais são compostos na sua fração graúda por menos de $90 \%$ em massa de fragmentos à base de cimento Portland e rochas [2].

Os agregados de resíduo de concreto (ARC) são geralmente indicados para se utilizar na produção de novos concretos, no entanto, ainda não se tem grande aplicação desse material no Brasil. A indústria da construção civil ainda é possuidora de grandes dúvidas sobre a utilização dos agregados reciclados na produção comercial de concreto, principalmente para fins estruturais, devido a algumas qualidades desfavoráveis destes agregados comparado aos naturais [3].

Os agregados de resíduo de concreto (ARC) são compostos comumente pelo agregado natural revestido por camadas de argamassa antiga, logo, devido a essa característica, estes agregados possuem massa específica relativamente menor do que os agregados naturais. Além disso, a camada de argamassa aderida possui maior porosidade, o que faz com que o agregado reciclado absorva mais água, entre 4 e 9,5\%, quando comparado ao agregado natural [4]. A argamassa aderida é responsável pela baixa resistência a ações mecânicas e químicas dos ARC [5].

A microestrutura do concreto com agregado reciclado é mais heterogênea do que a do concreto convencional, pois o mesmo possui duas zonas de transição, uma entre o ARC e a nova argamassa e outra entre o agregado original e a antiga argamassa aderida [6]. A presença de argamassa antiga aderida aos ARC é significativa para as propriedades do concreto com agregado reciclado, considerando que os ARC consistem em $65-70 \%$ em volume de agregado graúdo natural e 30 - $35 \%$ em volume de pasta de cimento antiga [7].

\subsection{Características do concreto produzido com agregados de resíduo de concreto}

Devido a maior porosidade dos agregados reciclados, na produção do concreto com ARC substituindo o agregado natural, geralmente é necessário acrescentar água adicional para conseguir o mesmo abatimento do concreto referência. No estudo de TABSH e ABDELFATAH [8] foi necessário acrescentar cerca de $10 \%$ a mais de água para conseguir o abatimento equivalente ao do concreto referência $(100 \mathrm{~mm})$.

ETXEBERRIA, VÁZQUEZ, MARÍ et al. [9] observaram que o concreto produzido com a substituição de $25 \%$ do agregado natural por agregado de resíduo de concreto apresentou resistência à compressão similar ao concreto convencional. Já na substituição de $100 \%$ do agregado natural por agregado reciclado, os autores observaram um decréscimo de 20-25\% da resistência à compressão em relação ao concreto convencional, utilizando a mesma relação água/cimento (a/c) efetiva e a mesma quantidade de cimento. THOMAS, SETIÉN, POLANCO et al. [10] observaram que a substituição do agregado natural por ARC no teor de $20 \%$, considerando a água de absorção do ARC, não provocou alterações significativas na resistência à compressão em relação ao concreto convencional, aos 28 dias.

$\mathrm{O}$ concreto com ARC e o concreto referência apresentam um perfil semelhante no que diz respeito ao aumento da resistência à compressão com a idade, no entanto, há uma tendência decrescente na resistência à compressão em relação ao alto nível do teor de ARC. A relação inversa entre o teor de ARC e a resistência à compressão deve-se à má qualidade da antiga argamassa aderida aos agregados reciclados, o que gera regiões 
mais fracas no concreto [5].

A influência do ARC no módulo de elasticidade é maior do que na resistência à compressão [10]. O módulo de elasticidade do concreto com agregado reciclado reduz à medida que o teor de ARC aumenta, e geralmente a redução do módulo de elasticidade do concreto com agregado reciclado deve-se à grande quantidade de argamassa antiga aderida [11]. Conforme CHEN [12], o módulo de elasticidade do concreto com agregado reciclado diminuiu em torno de $22,8 \%$ quando a taxa de substituição foi $50 \%$ e $44,3 \%$ quando o ARC substituiu totalmente o agregado natural. KOU et. al, [13] também observaram um decréscimo, aos 28 dias, de $40 \%$ do módulo de elasticidade quando o ARC substituiu $100 \%$ do agregado natural.

Já em relação à resistência à tração, XIAO e LAN [14], observaram uma queda de 10 - $35 \%$ da resistência no concreto com $100 \%$ de agregado de resíduo de concreto. BHASYA e BHARATKUMAR [15] analisaram concretos com $50 \%$ e $100 \%$ de ARC, e aos 28 dias obtiveram valores menores em torno de $15 \%$ e $17 \%$, respectivamente, quando comparados ao concreto convencional.

Quando comparado ao concreto com agregado natural, a durabilidade do concreto com ARC é reduzida. A impermeabilidade do concreto com agregado reciclado é governada especialmente pelo teor de ARC, relação a/c e idade de cura, sendo geralmente mais fraca do que o concreto convencional [1].

O ensaio de absorção de água por imersão é utilizado para avaliar a porosidade aberta do concreto, a qual é dependente da porosidade do agregado, do ar aprisionado inerente ao processo de mistura e do excesso de água além da necessária à hidratação do cimento. ALEXANDRIDOU, ANGELOPOULOS e COUTELIERIS [16] analisaram a substituição do agregado natural por ARC, e observaram que a absorção de água do concreto aumenta linearmente com o aumento do teor de substituição, sendo esta tendência observada também no volume de poros abertos. Foi observado um aumento de $15 \%$ da absorção de água por imersão e $13 \%$ do volume de poros abertos no concreto com $25 \%$ de ARC em relação ao concreto referência. Segundo GUO, SHI, GUAN et al. [1], o concreto com $100 \%$ de agregado reciclado pode ter cerca de 2,47 vezes maior absorção de água por imersão do que o concreto referência.

A penetração de íons cloreto e a carbonatação são os principais fatores responsáveis pela despassivação da armadura de concreto. De acordo com o estudo de BRAVO, DE BRITO, PONTES et al. [17], a utilização de agregados reciclados no concreto indica um ligeiro aumento do coeficiente de difusão de íons cloreto em relação ao concreto convencional. Foi observado nesse estudo que o aumento do período de cura das misturas levou a uma diminuição na penetração de íons cloreto. Já com relação à carbonatação, conforme os autores, os concretos com agregados reciclados possuem menor resistência do que o concreto convencional.

Se tratando da resistividade elétrica do concreto, o concreto com $50 \%$ de ARC pode possuir até $32 \%$ menor resistividade comparado ao concreto convencional. Este comportamento pode ser atribuído à maior permeabilidade, presença de argamassa residual porosa e fissurada e a disponibilidade de zona de transições danificadas [18].

\subsection{Tratamentos em agregados de resíduo de concreto}

$\mathrm{Na}$ busca de melhorar a qualidade dos agregados de resíduo de concreto, várias técnicas vêm sendo desenvolvidas. Uma das formas de proporcionar essa melhoria é através da modificação da superfície dos agregados reciclados.

Alguns pesquisadores utilizaram abordagens diferentes para promover a modificação na superfície dos ARC. Na Tabela 1 é apresenta uma síntese de alguns estudos que produziram concretos utilizando ARC com a superfície modificada.

Durante a primeira etapa de mistura, a abordagem TSMA (Two-Stage Mixing Approach) usa metade da água necessária para a formação de uma fina camada de pasta de cimento na superfície do agregado reciclado, a qual irá penetrar na argamassa de cimento antiga e porosa, preenchendo as fissuras e vazios antigos. Já no segundo estágio, a água restante é adicionada para completar o processo de mistura do concreto [19]. Para TAM e TAM [20], o método de mistura de dois estágios favorece uma melhor ligação agregado-matriz, associada à formação de uma zona de transição menos porosa e um melhor intertravamento entre a pasta e o agregado. Segundo GÜNEYISI, GESOGLU, ALGIN et al. [22], este processo gera um concreto com microestrutura mais densa e conectada comparada ao concreto com agregados reciclados sem tratamento. 
Tabela 1: Síntese de estudos que buscaram proporcionar melhorias na superfície dos agregados de resíduo de concreto.

\begin{tabular}{|c|c|c|c|}
\hline AUTOR & $\begin{array}{l}\text { CARACTERÍSTI- } \\
\text { CAS DA DOSAGEM }\end{array}$ & PRINCÍPIO DO TRATAMENTO & RESULTADOS \\
\hline $\begin{array}{l}\text { TAM, GAO } \\
\text { e TAM [19] }\end{array}$ & $\begin{array}{l}\text { Relação a/c: } 0,45 \\
\text { Teor de substituição } \\
\text { de ARC: } 20 \% \mathrm{e} \\
30 \%\end{array}$ & $\begin{array}{l}\text { - Abordagem de mistura dois estágios } \\
\text { (two-stage mixing approach) - } \\
\text { TSMA: } \\
1^{\circ} \text { estágio de mistura: agregados miú- } \\
\text { dos + agregados graúdos (naturais e } \\
\text { reciclados) }+50 \% \text { da água necessária } \\
+ \text { cimento Portland. } \\
2^{\circ} \text { estágio de mistura: } 50 \% \text { da água } \\
\text { remanescente. }\end{array}$ & $\begin{array}{l}\text { Ganho na resistência à compressão } \\
\text { aos } 28 \text { dias de } 21,3 \% \text { e } 14 \% \text { para o } \\
\text { concreto preparado com } 20 \% \text { e } 30 \\
\% \text { de ARC, respectivamente, na } \\
\text { abordagem TSMA, em comparação } \\
\text { ao método de mistura normal - } \\
\text { NMA (o qual adiciona todos os } \\
\text { materiais de uma única vez). }\end{array}$ \\
\hline \multirow[b]{2}{*}{$\begin{array}{l}\text { TAM e } \\
\text { TAM [20] }\end{array}$} & \multirow{2}{*}{$\begin{array}{l}\text { Relação a/c: } 0,45 \\
\text { Teor de substituição } \\
\text { de ARC: } 20 \% \text { e } \\
30 \%\end{array}$} & $\begin{array}{l}\text { Abordagem de mistura dois estágios } \\
\text { com sílica ativa - TSMAs: } \\
1^{\circ} \text { estágio de mistura: } 2 \% \text { de sílica } \\
\text { ativa substituindo o cimento (na pro- } \\
\text { porção de ARC utilizado) + ARC + } \\
50 \% \text { da água necessária. } \\
2^{\circ} \text { estágio de mistura: agregados miú- } \\
\text { dos e graúdos naturais + cimento } \\
\text { Portland + } 50 \% \text { da água remanescen- } \\
\text { te. }\end{array}$ & $\begin{array}{l}\text { Abordagem TSMAs: Ganho na } \\
\text { resistência à compressão aos } 28 \\
\text { dias de } 1,97 \% \text { e } 6,49 \% \text { para os } \\
\text { teores de } 20 \% \text { e } 30 \% \text { de ARC, } \\
\text { respectivamente, comparados ao } \\
\text { método de mistura convencional. }\end{array}$ \\
\hline & & $\begin{array}{l}\text { Abordagem de mistura dois estágios } \\
\text { com sílica ativa e cimento - TSMAsc: } \\
1^{\circ} \text { estágio de mistura: cimento Por- } \\
\text { tland (proporcionalmente à porcenta- } \\
\text { gem de ARC) + sílica ativa ( } 2 \% \text { em } \\
\text { substituição ao cimento) + ARC + } \\
50 \% \text { da água necessária. } \\
2^{\circ} \text { estágio de mistura: agregados miú- } \\
\text { dos e graúdos naturais + restante do } \\
\text { cimento Portland + } 50 \% \text { da água } \\
\text { remanescente. }\end{array}$ & $\begin{array}{l}\text { Abordagem TSMAsc: Melhoria na } \\
\text { resistência à compressão aos } 28 \\
\text { dias de } 12,87 \% \text { e } \\
6,51 \% \text { para os teores de } 20 \% \text { e } 30 \\
\% \text { de ARC, respectivamente, com- } \\
\text { parando ao método de mistura con- } \\
\text { vencional. }\end{array}$ \\
\hline $\begin{array}{l}\text { ZHIHUI, } \\
\text { SHOUDE, } \\
\text { LING- } \\
\text { CHAO et } \\
\text { al. }[21]\end{array}$ & $\begin{array}{l}\text { Relação a/c: } 0,48 \\
\text { Teor de substituição } \\
\text { de ARC: } 30 \%\end{array}$ & $\begin{array}{l}\text { Os ARC foram adicionados em uma } \\
\text { pasta de cimento Portland, uniforme- } \\
\text { mente agitados e imersos durante o } \\
\text { período de } 5 \text { a } 10 \text { minutos e poste- } \\
\text { riormente foram secos ao ar natural. } \\
\text { Comparou-se o efeito no concreto de } \\
5 \text { pastas distintas no processo de tra- } \\
\text { tamento dos ARC, com o concreto } \\
\text { produzido com ARC sem tratamento. } \\
\text { (1) ARC sem tratamento } \\
\text { (2) Cimento Portland e a/c de } 0,5 \text {; } \\
\text { (3) Cimento Portland e a/c de } 0,6 \text {; } \\
\text { (4) Cimento Portland e a/c de } 0,7 \\
\text { (5) Cimento Portland e a/c de } 0,8 \text {; } \\
\text { (6) Cimento Portland e a/c de } 1,0 \text {. }\end{array}$ & $\begin{array}{l}\text { A resistência à compressão dos } \\
\text { concretos com ARC tratados foram } \\
\text { maiores do que a do concreto com } \\
\text { ARC sem tratamento. } \\
\text { Aos } 28 \text { dias, foram obtidos os se- } \\
\text { guintes valores: } \\
\text { (1) ARC }=52,0 \mathrm{MPa} \\
\text { (2) ARC }-0,5=57,0 \mathrm{MPa} \\
\text { (3) ARC }-0,6=56,0 \mathrm{MPa} \\
\text { (4) ARC }-0,7=57,2 \mathrm{MPa} \\
\text { (5) ARC }-0,8=59,5 \mathrm{MPa} \\
\text { (6) ARC }-1,0=58,0 \mathrm{MPa}\end{array}$ \\
\hline $\begin{array}{l}\text { GÜNE- } \\
\text { YISI, GE- } \\
\text { SOGLU, } \\
\text { ALGIN et } \\
\text { al. }[22]\end{array}$ & $\begin{array}{l}\text { Relação a/agl: } 0,38 \\
\text { Teor de substituição } \\
\text { de ARC: } 100 \%\end{array}$ & $\begin{array}{l}\text { Abordagem de mistura dois estágios: } \\
1^{\circ} \text { estágio de mistura: cimento } \\
\text { Portland + cinza volante }+ \text { ARC. } \\
2^{\circ} \text { estágio de mistura: Agregados } \\
\text { miúdos e graúdos naturais. }\end{array}$ & $\begin{array}{l}\text { O concreto preparado com ARC } \\
\text { tratados pelo método dois estágios } \\
\text { apresentou melhorias de } \\
13 \% \text { e } 10 \% \text {, aos } 28 \text { e } 90 \text { dias, res- } \\
\text { pectivamente, comparado ao con- } \\
\text { creto com ARC sem tratamento. }\end{array}$ \\
\hline KATZ [23] & $\begin{array}{l}\text { Relação a/c: } 0,53 \\
\text { Teor de substituição } \\
\text { de ARC: } 100 \%\end{array}$ & $\begin{array}{l}\text { Imersão dos ARC durante } 24 \text { horas } \\
\text { em uma pasta composta por água, } \\
\text { sílica ativa e superplastificante. Após } \\
\text { as } 24 \text { horas, os ARC foram secos no } \\
\text { forno, para a posterior aplicação no } \\
\text { concreto. }\end{array}$ & $\begin{array}{l}\text { Melhoria aos } 28 \text { dias de } 13 \% \text { a } 16 \\
\% \text {, dependendo da resistência do } \\
\text { concreto que deu origem ao ARC, } \\
\text { comparado ao concreto com ARC } \\
\text { sem tratamento. }\end{array}$ \\
\hline
\end{tabular}

TAM e TAM [24] estudaram a permeabilidade à água, ao ar e a cloretos, buscando relacioná-las à durabilidade dos concretos produzidos pela abordagem TSMA. Em relação à permeabilidade à água, obser- 
varam uma redução de 2,34 \% aos 28 dias de idade, da mistura realizada pelo método TSMA com $20 \%$ de ARC em comparação à mistura realizada pelo método normal (NMA). Já na permeabilidade a cloretos, foi observada uma redução de 22,78 \% e $0,70 \%$ da TSMA em relação à NMA, aos 28 e 98 dias, respectivamente.

ZHIHUI, SHOUDE, LINGCHAO et al. [21] observaram que a absorção de água dos ARC prérevestidos diminuiu com o aumento da relação a/c da pasta, enquanto a densidade aparente aumentou. Este fato foi atribuído à maior facilidade de absorção da pasta com menor relação a/c pela porosidade do ARC, no momento do tratamento. De acordo com os resultados, a pasta de revestimento muito grossa ou muito fina foram ambas ruins para a melhoria do desempenho físico do ARC pré-revestido.

Esse estudo possui como objetivo verificar o efeito da substituição de $20 \%$ de agregado graúdo natural por ARC no concreto e realizar a modificação da superfície dos ARC através de dois teores de cimento Portland ( 25 e $100 \%$ ) na abordagem de mistura dois estágios, observando qual teor proporcionou melhorias mais significativas em relação às propriedades mecânicas e em alguns parâmetros de durabilidade.

\section{MATERIAIS E MÉTODOS}

\subsection{Materiais}

Foi utilizado na produção dos concretos o cimento Portland de alta resistência inicial (CP V - ARI), o qual foi escolhido devido à maior porcentagem de clínquer dentre os disponíveis no mercado, ou seja, o mais puro possível.

O aditivo utilizado foi o Glenium 51, superplastificante (SP) à base de éter policarboxílico com longas cadeias laterais. Já a água de amassamento foi fornecida pela companhia de abastecimento de água da região de Brasília - DF, isenta de impurezas visíveis.

Como agregado miúdo natural foi utilizada a areia lavada de rio. Já os agregados graúdos naturais foram provenientes da britagem de rocha calcária, sendo realizada uma composição de agregados com $70 \%$ de brita de $19,0 \mathrm{~mm}$ e $30 \%$ de brita de $12,5 \mathrm{~mm}$ de diâmetro máximo. O agregado graúdo reciclado utilizado para substituir parcialmente o agregado graúdo natural, foi oriundo de resíduo de concreto, proveniente do fornecedor Areia Bela Vista, localizado em Sobradinho, região norte de Brasília - DF.

\subsection{Dosagem dos concretos}

A dosagem dos concretos foi realizada buscando analisar o efeito da substituição volumétrica parcial do agregado graúdo natural por agregado graúdo reciclado, além da utilização de tratamentos para modificação da superfície destes. A dosagem nesta pesquisa foi baseada no método IPT/EPUSP de HELENE e TERZIAN [25]. Foi fixada uma relação a/c de 0,50 com o objetivo de atender as classes de agressividade ambiental III e IV da ABNT NBR 6118:2014.

Foi realizado um estudo de dosagem experimental para determinar o teor de argamassa ideal, sendo este de $52 \%$. A consistência pelo abatimento do tronco de cone foi fixada em $150 \pm 10 \mathrm{~mm}$. Para atingir esta consistência, foi necessária a utilização de aditivo superplastificante. Após a dosagem do concreto referência, foram fixados o teor de argamassa ideal, a relação água/material seco e a consistência para a determinação dos demais traços. Foi necessário utilizar um teor de $0,38 \%$ de aditivo superplastificante para todos os traços (inclusive para o concreto referência), calculado sobre a massa de cimento utilizada.

Foram produzidas quatro composições de concreto, as quais foram denominadas como: CREF, CARC20-MN, CARC20-DE100 e CARC20-DE25. Na Tabela 2 são apresentadas as nomenclaturas dadas aos concretos e suas respectivas características.

A substituição dos agregados graúdos naturais por agregados graúdos reciclados foi realizada volumetricamente, considerando a curva de distribuição granulométrica do agregado graúdo natural (Figura 4), sendo substituído nas proporções correspondentes a cada fração granulométrica. 
Tabela 2: Nomenclatura e características das composições de concreto.

\begin{tabular}{l|l}
\hline COMPOSIÇÃo & CARACTERístiCA \\
\hline CREF & Concreto referência (sem ARC). \\
\hline CARC20-MN & $\begin{array}{l}\text { Concreto com } 20 \% \text { de ARC, utilizando o método de mistura normal } \\
\text { (MN). }\end{array}$ \\
\hline CARC20-DE100 & $\begin{array}{l}\text { Concreto com } 20 \% \text { ARC, utilizando o método de mistura dois estágios } \\
\text { (DE) com 100\% de cimento Portland. }\end{array}$ \\
\hline CARC20-DE25 & $\begin{array}{l}\text { Concreto com 20\% ARC, utilizando o método de mistura dois estágios } \\
\text { (DE) com 25\% de cimento Portland. }\end{array}$ \\
\hline
\end{tabular}

Nos concretos com ARC se fez necessário ainda considerar a água adicional referente à absorção total do agregado reciclado, determinada através do ensaio de absorção de água. Foi considerado no cálculo da quantidade total de água, $100 \%$ do valor de absorção de água do ARC. Desta forma, a relação a/c efetiva das composições com agregado reciclado tornou-se maior. Na Tabela 3 estão apresentadas as composições produzidas nesta pesquisa.

Tabela 3: Composição dos concretos.

\begin{tabular}{l|l|l|l|l}
\hline COMPOSIÇÃO & CREF & CARC20-MN & CARC20-DE100 & CARC20-DE25 \\
\hline CIMENTO & 1,00 & 1,00 & 1,00 & 1,00 \\
\hline AREIA & 2,12 & 2,12 & 2,12 & 2,12 \\
\hline $\begin{array}{l}\text { AGREGADO GRAÚDO RECI- } \\
\text { CLADO }\end{array}$ & 0,00 & 0,54 & 0,54 & 0,54 \\
\hline BRITA 19,0 MM & 2,02 & 1,61 & 1,61 & 1,61 \\
\hline BRITA 12,5 MM & 0,86 & 0,69 & 0,69 & 0,69 \\
\hline ADITIVO SP (\%) & 0,38 & 0,38 & 0,38 & 0,38 \\
\hline RELAÇÃO A/C & 0,50 & 0,50 & 0,50 & 0,50 \\
\hline RELAÇÃO A/C EFETIVA & 0,50 & 0,52 & 0,52 & 0,52 \\
\hline
\end{tabular}

Em relação ao procedimento de mistura dos materiais durante a produção dos concretos, foi utilizada uma pré-molhagem dos agregados reciclados por 20 minutos no concreto CARC20-MN. Este tempo de prémolhagem foi determinado experimentalmente através do ensaio de absorção de água do agregado reciclado, conforme o modelo proposto por LEITE [26]. Na Figura 1 está apresentada a curva de absorção do ARC, obtida através do ensaio de absorção por 60 minutos.

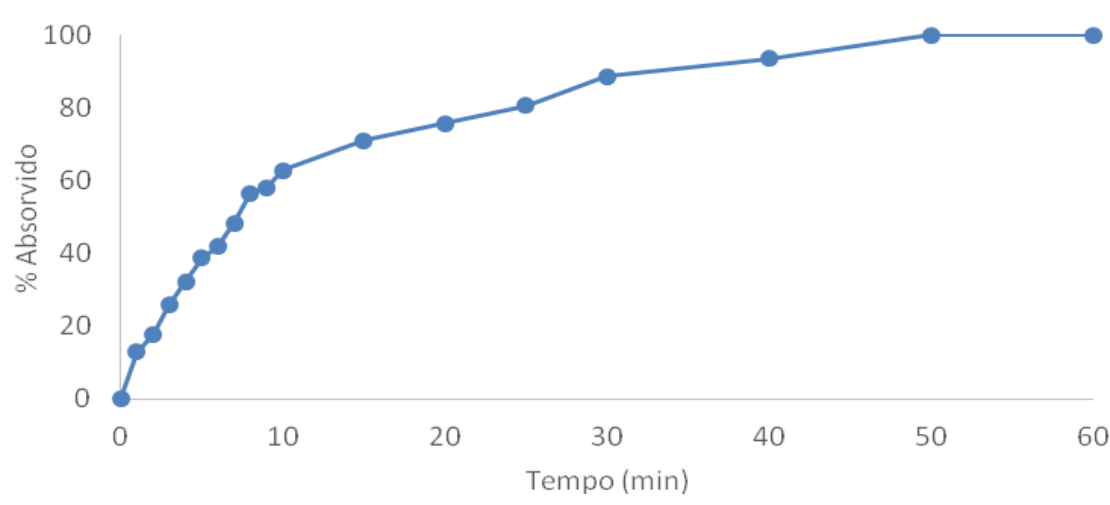

Figura 1: Curva de absorção do agregado de resíduo de concreto.

Considera-se que no intervalo de tempo de 20 minutos estes agregados absorvem aproximadamente $80 \%$ da água, evitando assim, a absorção da água da matriz cimentícia por parte destes. A água utilizada no procedimento de pré-molhagem foi a mesma empregada na produção do concreto, e foi adicionada de forma 
que cobrisse todos os agregados reciclados utilizados na dosagem.

Após a etapa de pré-molhagem, foi acrescentado o restante dos materiais e acionada a betoneira para que ocorresse o processo de mistura. $\mathrm{O}$ aditivo superplastificante foi adicionado para atingir a consistência requerida. O procedimento de mistura dois estágios (CARC20-DE100 e CARC20-DE25), considerada uma forma de tratamento para os ARC, será abordado no item 2.3.

Após as dosagens, foram moldados os corpos de prova cilíndricos de 100 × $200 \mathrm{~mm}$, sendo adensados com a utilização de um vibrador, de acordo com a ABNT NBR 5738:2015 [27]. Durante as primeiras 24 horas, os corpos de prova foram armazenados em ambiente laboratorial e devidamente cobertos com placas de vidro para evitar a perda de água do concreto. Em seguida, foram desmoldados e colocados na câmara úmida até a data de realização dos ensaios.

\subsection{Tratamentos nos agregados de resíduo de concreto}

$\mathrm{O}$ tratamento adotado para proporcionar melhoria nos agregados de resíduo de concreto foi a abordagem de mistura dois estágios. O método consistiu em dividir o processo de mistura dos materiais em dois estágios, como o próprio nome indica.

Buscando avaliar qual o teor de cimento Portland utilizado na pré-mistura ( $1^{\circ}$ estágio) que melhor satisfaz as propriedades do concreto, foram analisadas duas variações da abordagem de mistura dois estágios: CARC20-DE100 e CARC20-DE25.

Na mistura CARC20-DE100, no primeiro estágio foi adicionada a água de dosagem, o cimento Portland (100\% do requerido) e os ARC. Os agregados reciclados permaneceram imersos na pasta de cimento por 20 minutos (período determinado através da curva de absorção conforme o item 2.2). Após os 20 minutos, iniciou-se o segundo estágio, adicionando e misturando os agregados miúdos e graúdos naturais e o aditivo superplastificante.

Já na mistura CARC20-DE25, no primeiro estágio foi adicionada a água de dosagem, o cimento Portland ( $25 \%$ do requerido) e os ARC. O período de permanência dos ARC na pasta também foi de 20 minutos. Em seguida, no segundo estágio, foi adicionado o restante do cimento Portland, os agregados miúdos e graúdos naturais e o superplastificante.

Na Figura 2 são apresentados os processos de pré-molhagem para o concreto CARC20-MN e o primeiro estágio da abordagem de mistura dois estágios (com 100 e $25 \%$ de cimento Portland) para os concretos CARC20-DE100 e CARC20-DE25, respectivamente.
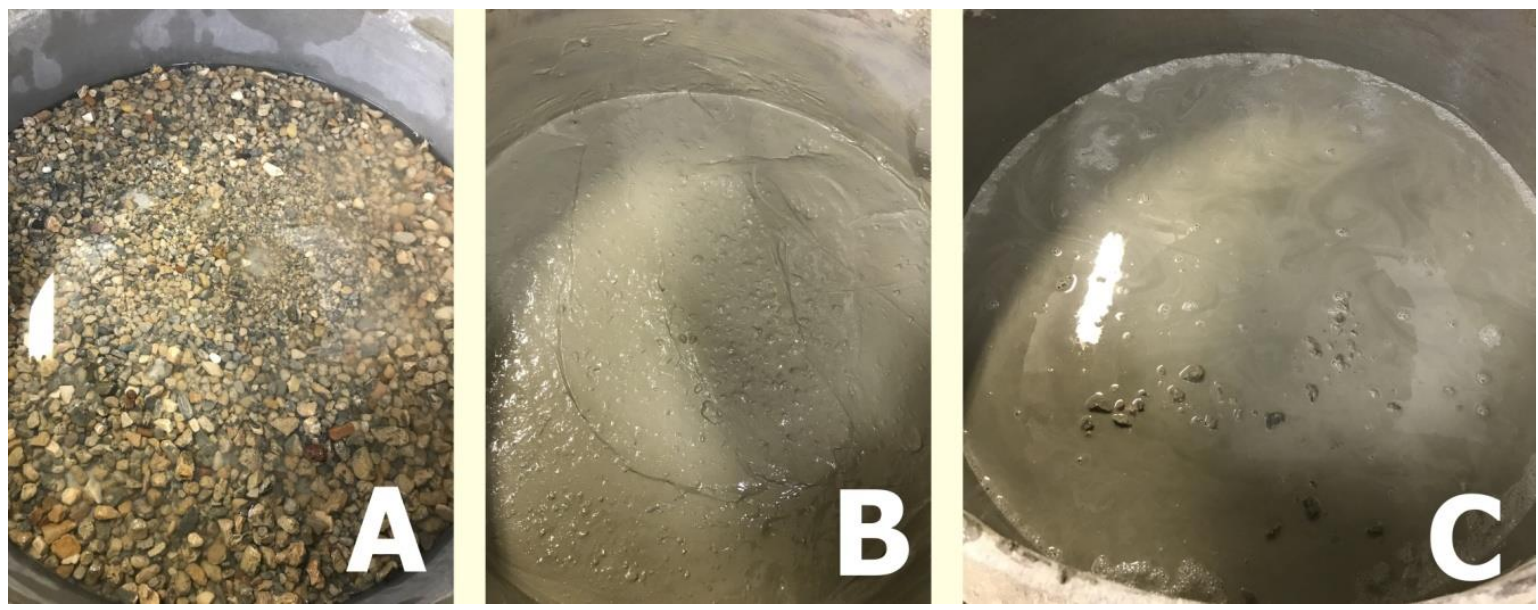

Figura 2: (A) - Etapa de pré-molhagem do CARC20-MN; (B) $1^{\circ}$ estágio de mistura do CARC20-DE100; (C) $1^{\circ}$ estágio de mistura do CARC20-DE25.

\subsection{Análise dos concretos no estado fresco e das propriedades mecânicas}

Para a análise dos concretos no estado fresco, foram realizados os ensaios de determinação da consistência pelo abatimento do tronco de cone, conforme a ABNT NBR NM 67:1998 [28] e massa específica de acordo com as recomendações do IPT/EPUSP de HELENE e TERZIAN [25].

Já para analisar as propriedades mecânicas foram realizados os ensaios de resistência à compressão simples (ABNT NBR 5739:2018 [29]) nas idades de 7, 28 e 91 dias, resistência à tração por compressão di- 
ametral (ABNT NBR 7222:2011 [30]) na idade de 28 dias e módulo estático de elasticidade à compressão (ABNT NBR 8522:2008 [31]) aos 28 dias de idade.

\subsection{Análise da durabilidade dos concretos}

Para analisar alguns critérios de durabilidade dos concretos, foram realizados os ensaios de absorção de água por imersão, resistividade elétrica (volumétrica e superficial), carbonatação acelerada, migração de cloretos no estado não estacionário e efeito combinado da carbonatação acelerada seguida da migração de cloretos no estado não estacionário.

Todos os ensaios de durabilidade foram realizados nos concretos com 91 dias de idade. $\mathrm{O}$ ensaio de migração de cloretos no estado não estacionário, além de ser realizado nessa idade, também foi realizado aos 28 dias.

\subsubsection{Absorção de água por imersão}

O ensaio de absorção de água por imersão foi realizado conforme as recomendações da ABNT NBR 9778:2005 [32]. Este ensaio além de apontar o índice de vazios do concreto, também fornece um bom indicador para avaliar a porosidade aberta, acessível à água.

\subsubsection{Resistividade elétrica}

A resistividade elétrica dos concretos foi avaliada por dois métodos: o volumétrico e o superficial. O ensaio de resistividade elétrica volumétrica foi realizado de acordo com a AASHTO TP 119-15 [33]. Neste ensaio, um conjunto de placas de aço inoxidável foi utilizado como eletrodos, entre os quais a amostra de concreto foi colocada. Em seguida, uma corrente elétrica foi aplicada às placas e a diferença de potencial elétrico correspondente foi medida. Sendo assim, a corrente elétrica passou por toda a extensão do corpo de prova, ou seja, da base ao topo.

Já o ensaio de resistividade elétrica superficial foi realizado baseado na ASTM G57-06: 2012 [34]. Na execução do ensaio foi utilizado um aparato com 4 eletrodos igualmente espaçados entre si, os quais ficaram em contato com a superfície lateral do corpo de prova de concreto. Desta forma, uma corrente alternada foi aplicada nos eletrodos externos e a partir dos eletrodos internos foi realizada a medida da diferença de potencial elétrico.

\subsubsection{Carbonatação acelerada}

O ensaio de carbonatação acelerada foi realizado utilizando corpos de prova cilíndricos com dimensões de 100 x 200 mm e com os parâmetros da câmara de carbonatação conforme as exigências da ISO 1920-12:2015 [35]. Baseado na norma, as condições utilizadas para este ensaio foram: temperatura de $27 \pm 2{ }^{\circ} \mathrm{C}$, umidade relativa equivalente a $65 \pm 5 \%$ e concentração de $\mathrm{CO}_{2}$ de $3,0 \pm 0,5 \%$, em volume.

\subsubsection{Migração de cloretos no estado não estacionário}

O ensaio de migração de cloretos no estado não estacionário foi realizado de acordo com a NT BUILD 492:2011[36]. Para este ensaio foram confeccionados corpos de prova cilíndricos com dimensões de $100 \mathrm{x}$ $200 \mathrm{~mm}$, os quais foram posteriormente cortados em quatro partes iguais de 100 x $50 \mathrm{~mm}$, utilizando-se para o ensaio as duas amostras centrais. Antes da realização do ensaio, as amostras passaram por um précondicionamento de acordo com as recomendações da norma. Posteriormente, as amostras foram fixadas em aparatos, os quais foram posicionados em um recipiente plástico contendo solução catódica de $10 \%$ de cloreto de sódio em massa de água ( $100 \mathrm{~g}$ de $\mathrm{NaCl}$ para cada $900 \mathrm{~g}$ de água), e cada aparato contendo a amostra foi preenchido com uma solução anódica de hidróxido de sódio em água destilada $(1,2 \mathrm{~g}$ de $\mathrm{NaOH}$ para cada $100 \mathrm{~g}$ de água). Em seguida ocorreu a conexão em paralelo de todos os aparatos, ou seja, os cátodos foram ligados ao polo negativo e os ânodos ao polo positivo da fonte de corrente contínua, a qual foi ajustada inicialmente para $30 \mathrm{~V}$. Com o uso de um multímetro, foi medida a corrente inicial em cada amostra, e, em função dessa corrente inicial, o valor da tensão foi ajustado, conforme as recomendações normativas. Após o processo de migração de cloretos (período de ensaio conforme a norma), as amostras foram rompidas à tração por compressão diametral e foi aspergida na superfície fraturada de uma das metades da amostra, uma solução de nitrato de prata $\left(\mathrm{AgNO}_{3}\right)$ 0,1 molar, o qual permite a medição a frente de penetração de cloretos devido ao contraste visual formado na superfície da amostra. 


\subsubsection{Efeito combinado da carbonatação acelerada e migração de cloretos no estado não estacionário}

A análise do efeito combinado de carbonatação acelerada e migração de cloretos foi realizada através destes dois ensaios individualmente, seguido um do outro. Após 28 dias de cura os corpos de prova foram cortados em quatro partes iguais de 100 × $50 \mathrm{~mm}$, utilizando-se para os ensaios as duas amostras centrais. Em seguida, as amostras foram pré-condicionadas por 7 dias até ocorrer a estabilização da umidade interna, avaliada por meio da constância de massa. Posteriormente, foram levadas à câmara de carbonatação acelerada onde permaneceram por 56 dias. Depois do período de exposição ao $\mathrm{CO}_{2}$, as amostras foram submetidas ao ensaio de migração de cloretos no estado não estacionário. Após os períodos de cura, pré-condicionamento e carbonatação, o ensaio de migração de cloretos foi realizado aos 91 dias de idade. A escolha do período de duração de cada etapa se deu propositalmente, buscando realizar a comparação da penetração de cloretos nas amostras carbonatadas e não carbonatadas em concretos com a mesma idade (91 dias).

\subsection{Análise estatística}

A partir dos resultados obtidos na realização dos ensaios, foi realizada a análise de variância dos dados e o teste de Duncan, utilizando o software STATISTICA v10.

A análise de variância (ANOVA) identifica se as médias diferem de maneira significativa, ou seja, analisa se a variável independente influenciou sobre a variável dependente. Essa influência é indicada por meio do Valor-p, o qual também é denominado de probabilidade significativa. Cada hipótese foi testada a um nível de significância $(\alpha)$ de 0,05 , possuindo um nível de confiança de $95 \%$.

Ao realizar a análise de variância, quando o Valor-p foi inferior a 0,05, o efeito foi considerado significativo sobre a variável dependente, ou seja, teve influência sobre esta. Por outro lado, quando o Valor-p foi igual ou superior a 0,05 , o efeito não foi considerado significativo.

Nos casos em que a influência foi significativa, os dados foram submetidos à comparação múltipla de médias por meio do teste de Duncan, o qual agrupa as médias que não diferem de forma significativa entre si.

\section{RESULTADOS}

Nesta seção serão apresentados os resultados obtidos a partir do programa experimental. Inicialmente serão apresentados os resultados de caracterização dos materiais, seguido da avaliação dos concretos no estado fresco, propriedades mecânicas e, por fim, serão apresentados os resultados dos ensaios referentes à durabilidade dos concretos.

\subsection{Caracterização dos materiais}

Na Tabela 4 estão apresentados os resultados de caracterização do cimento Portland de alta resistência inicial (CP V - ARI) e dos agregados miúdos e graúdos. Já nas Figuras 3 e 4 estão apresentadas as curvas de distribuição granulométrica dos agregados naturais miúdos e graúdos, respectivamente.

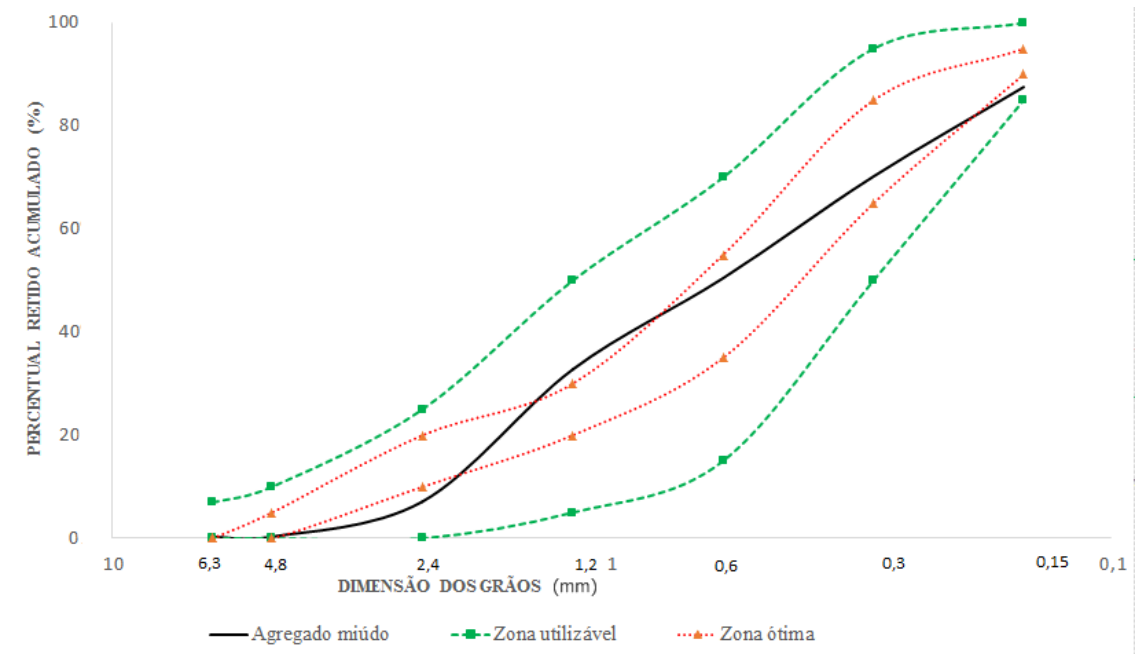

Figura 3: Curva granulométrica do agregado miúdo natural. 


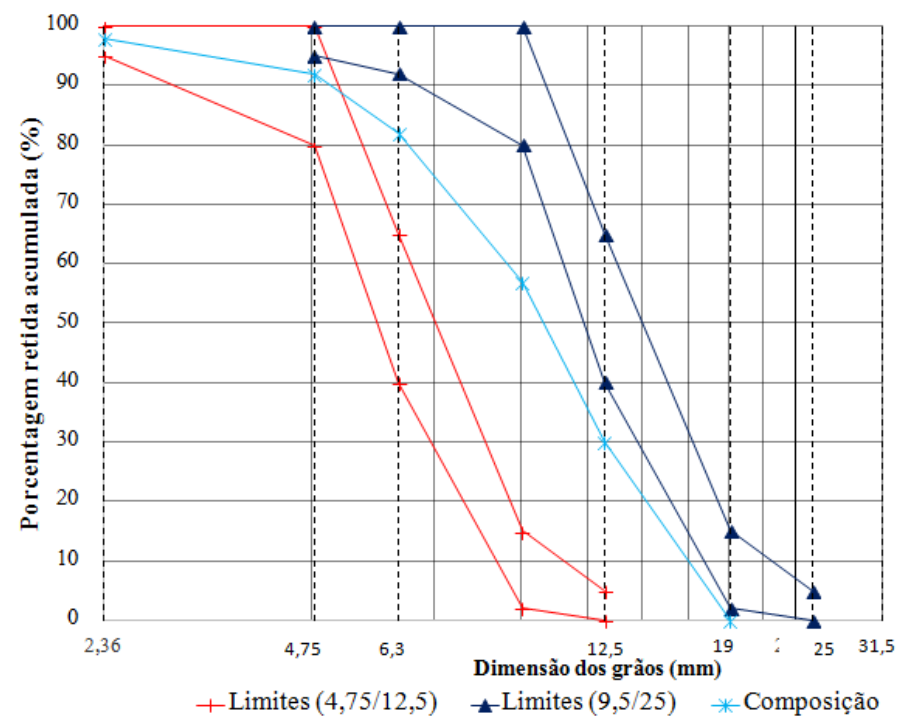

Figura 4: Curva granulométrica da composição de agregados graúdos naturais.

Tabela 4: Resultados de caracterização dos materiais.

\begin{tabular}{|c|c|c|c|c|c|}
\hline MATERIAL & \multicolumn{2}{|l|}{ PROPRIEDADES } & \multicolumn{2}{|c|}{ RESULTADOS } & MÉTODO \\
\hline \multirow{4}{*}{ CP V - ARI } & \multicolumn{2}{|c|}{ Massa específica $\left(\mathrm{g} / \mathrm{cm}^{3}\right)$} & \multicolumn{2}{|l|}{3,00} & ABNT NBR 16605:2017 [37] \\
\hline & \multicolumn{2}{|c|}{ Índice de finura (\%) } & \multicolumn{2}{|l|}{0,90} & ABNT NBR 11579:2012 [38] \\
\hline & \multirow{2}{*}{ Tempos de pega } & Início (min) & \multicolumn{2}{|l|}{120} & \multirow[t]{2}{*}{ ABNT NBR NM 65:2003 [39] } \\
\hline & & Fim (min) & \multicolumn{2}{|l|}{175} & \\
\hline \multirow{4}{*}{$\begin{array}{l}\text { Agregado miúdo } \\
\text { natural }\end{array}$} & \multicolumn{2}{|c|}{$\begin{array}{l}\text { Dimensão máxima característica } \\
(\mathrm{mm})\end{array}$} & \multicolumn{2}{|l|}{4,80} & \multirow[t]{2}{*}{ ABNT NBR NM 248:2003 [40] } \\
\hline & \multicolumn{2}{|c|}{ Módulo de finura (\%) } & \multicolumn{2}{|l|}{2,49} & \\
\hline & \multicolumn{2}{|c|}{ Massa específica $\left(\mathrm{g} / \mathrm{cm}^{3}\right)$} & \multicolumn{2}{|l|}{2,65} & ABNT NBR NM 52:2009 [41] \\
\hline & \multicolumn{2}{|c|}{ Massa unitária $\left(\mathrm{g} / \mathrm{cm}^{3}\right)$} & \multicolumn{2}{|l|}{1,49} & ABNT NBR NM 45:2006 [42] \\
\hline \multirow{4}{*}{$\begin{array}{l}\text { Agregado graúdo } \\
\text { reciclado }\end{array}$} & \multicolumn{2}{|c|}{$\begin{array}{l}\text { Dimensão máxima característica } \\
(\mathrm{mm})\end{array}$} & \multicolumn{2}{|l|}{12,50} & \multirow[t]{2}{*}{ ABNT NBR NM 248:2003 [40] } \\
\hline & \multicolumn{2}{|c|}{ Módulo de finura (\%) } & \multicolumn{2}{|l|}{5,02} & \\
\hline & \multicolumn{2}{|c|}{ Massa específica $\left(\mathrm{g} / \mathrm{cm}^{3}\right)$} & \multicolumn{2}{|l|}{2,58} & \multirow{3}{*}{ ABNT NBR NM 53:2009 [43] } \\
\hline & \multicolumn{2}{|c|}{ Absorção de água (\%) } & \multicolumn{2}{|l|}{3,71} & \\
\hline & & & BRITA 19 & BRITA 12,5 & \\
\hline \multirow{3}{*}{$\begin{array}{l}\text { Agregado graúdo } \\
\text { natural }\end{array}$} & \multicolumn{2}{|c|}{$\begin{array}{l}\text { Dimensão máxima característica } \\
(\mathrm{mm})\end{array}$} & 19,00 & 12,50 & \multirow[t]{2}{*}{ ABNT NBR NM 248:2003 [40] } \\
\hline & \multicolumn{2}{|c|}{ Módulo de finura (\%) } & 6,69 & 6,00 & \\
\hline & \multicolumn{2}{|c|}{ Massa específica $\left(\mathrm{g} / \mathrm{cm}^{3}\right)$} & 2,75 & 2,71 & ABNT NBR NM 52:2009 [41] \\
\hline
\end{tabular}

\subsection{Análise dos concretos no estado fresco e das propriedades mecânicas}

Na Tabela 5 são apresentados os valores de consistência, massa específica e o consumo de cimento para cada concreto produzido.

Em relação à consistência dos concretos, foi fixado o intervalo de $150 \pm 10 \mathrm{~mm}$ e para conseguir estes valores foi utilizado aditivo superplastificante. De acordo com a ABNT NBR 8953:2015 [44] e com os resultados de consistência, todos os concretos são classificados na classe de consistência "S100", os quais podem ser aplicados em elementos estruturais, com lançamento convencional. 
Tabela 5: Resultados dos ensaios realizados na avaliação dos concretos no estado fresco.

\begin{tabular}{l|l|l|l}
\hline COMPOSIÇÃO & $\begin{array}{l}\text { CONSISTÊNCIA PELO ABATI- } \\
\text { MENTO DO TRONCO DE CONE } \\
(\mathbf{m m})\end{array}$ & MASSA ESPECÍFICA (kg/m $\mathbf{3})$ & $\begin{array}{l}\text { CONSUMO DE CIMENTO } \\
\mathbf{( k g / \mathbf { m } ^ { 3 } )}\end{array}$ \\
\hline CREF & 150,00 & 2393,68 & 368,26 \\
\hline CARC20-MN & 148,00 & 2381,75 & 367,31 \\
\hline CARC20-DE100 & 150,00 & 2269,47 & 349,99 \\
\hline CARC20-DE25 & 145,00 & 2294,04 & 353,78 \\
\hline
\end{tabular}

Se tratando da massa específica no estado fresco e do consumo de cimento, foi observada pouca variação entre os concretos produzidos, indicando que a utilização de $20 \%$ de ARC e os tratamentos não influenciaram nestes aspectos.

Os ensaios de resistência à compressão simples foram realizados nos concretos aos 7, 28 e 91 dias de idade. Na Figura 5 está apresentada a evolução da resistência à compressão no decorrer dos dias.

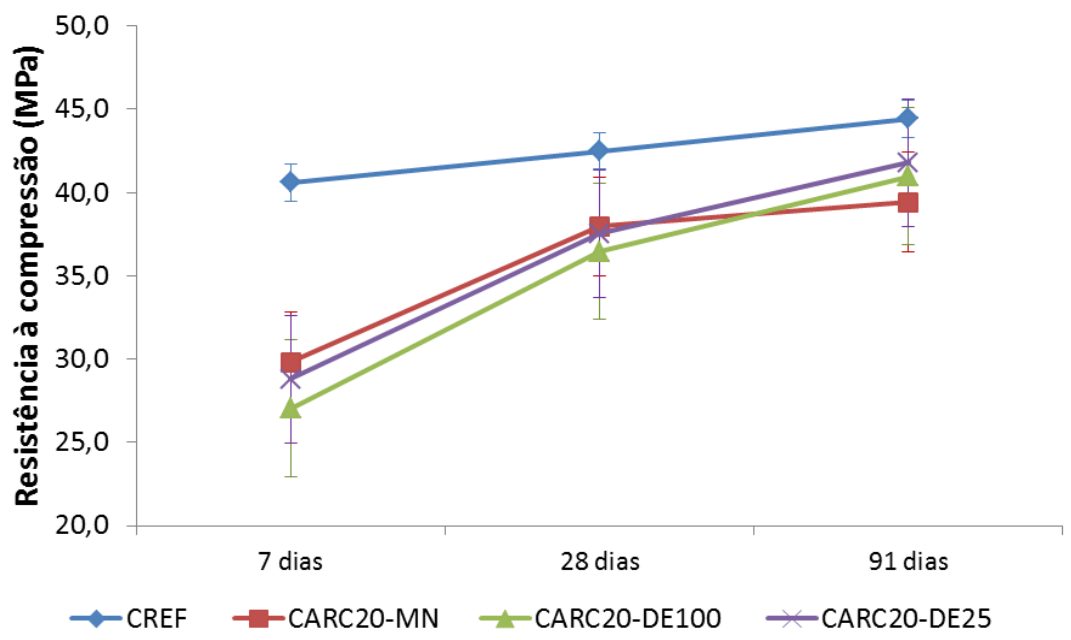

Figura 5: Evolução da resistência à compressão simples ao longo da idade de cura dos concretos.

É possível observar que todos os concretos apresentaram um ganho de resistência ao longo das idades, o que corrobora com o observado por KWAN, RAMLI, KAM et al. [5], os quais observaram um perfil semelhante entre o concreto com ARC e o concreto referência no que diz respeito ao aumento da resistência à compressão com a idade.

Aos 28 dias de idade, o CARC20-MN apresentou uma resistência à compressão ligeiramente superior aos concretos com ARC preparados com a abordagem de mistura dois estágios (CARC20-DE100 e CARC20-DE25). No entanto, aos 91 dias de idade ambos os concretos (CARC20-DE100 e CARC20-DE25) conseguiram superar a resistência do CARC20-MN.

A realização do tratamento nos ARC com a utilização da abordagem de mistura dois estágios com $25 \%$ de cimento Portland proporcionou melhoria de 6,0\% aos 91 dias de idade, sendo este efeito menos notável com a mistura dois estágios com $100 \%$ de cimento Portland, a qual foi equivalente a 4,0 \%. Estes resultados estão condizentes com o estudo de TAM, GAO e TAM [19], o qual observou um ganho de resistência de 21,3\% para o concreto preparado com $20 \%$ de ARC na abordagem de mistura dois estágios em relação ao preparado no método de mistura normal.

O fato da melhoria ter sido mais notável para o CARC20-DE25 do que para o CARC20-DE100, provavelmente ocorreu devido ao primeiro concreto possuir uma relação a/c maior no processo de pré-mistura ( $1^{\circ}$ estágio), o que favorece a penetração da pasta para o interior dos ARC. Esta observação está de acordo com a pesquisa de ZHIHUI, SHOUDE, LINGCHAO et al. [21], a qual indicou que a resistência à compressão do concreto com ARC tratados tende a aumentar com o aumento da relação a/c da pasta de revestimento (utilizada no $1^{\circ}$ estágio). 
Ao realizar a análise de variância (ANOVA) foi obtido um Valor-p=0,4145 para a resistência à compressão aos 91 dias, indicando que a utilização de $20 \%$ de agregado de resíduo de concreto (mistura normal e dois estágios) não apresentou diferença significativa. Aos 91 dias de idade a diferença percentual da resistência à compressão entre o CREF e CARC20-DE25 foi de 6,22 \%. Este resultado satisfatório se deve à qualidade do ARC e ao fator de empacotamento destes, pois ao manter a distribuição granulométrica este fator não foi alterado. Sendo assim, a utilização de ARC não prejudicou de forma significativa a resistência à compressão do concreto.

A resistência à tração por compressão diametral dos concretos foi analisada aos 28 dias de idade. $\mathrm{Na}$ Figura 6 estão apresentados os valores médios obtidos neste ensaio.

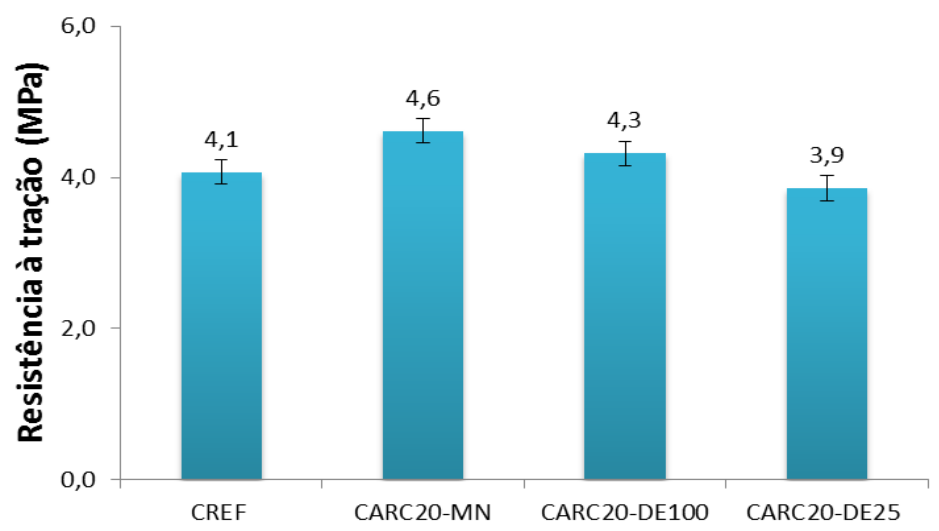

Figura 6: Valores médios da resistência à tração por compressão diametral aos 28 dias de idade.

Notou-se que todos os concretos apresentaram similaridade no que se refere a esta propriedade, considerando que os valores estão próximos. De acordo com a análise de variância (ANOVA), o Valor-p foi equivalente a 0,5080, confirmando a não significância da substituição de $20 \%$ do agregado natural por ARC (mistura normal e dois estágios) em relação à resistência à tração. Este resultado satisfatório também é atribuído à qualidade e ao fator de empacotamento dos $\mathrm{ARC}$, os quais não prejudicaram significativamente a resistência à tração ao serem utilizados na produção dos concretos.

Na Figura 7 estão apresentados os valores médios obtidos no ensaio de módulo estático de elasticidade à compressão, o qual também foi realizado aos 28 dias de idade. É notável a similaridade dos valores de módulo de elasticidade dos concretos (CREF, CARC20-MN e CARC20-DE25), porém houve uma redução de 24,5\% do módulo de elasticidade do CARC20-DE100 em relação ao CARC20-MN, indicando que a utilização de $100 \%$ de cimento Portland na abordagem de mistura dois estágios prejudicou o concreto nesta propriedade.

Analisando estatisticamente os valores de módulo de elasticidade, observou-se que a utilização de $20 \%$ de agregado de resíduo de concreto (mistura normal e dois estágios) apresentou diferença significativa nesta propriedade, considerando que a análise de variância (ANOVA) forneceu um Valor-p de 0,0000.

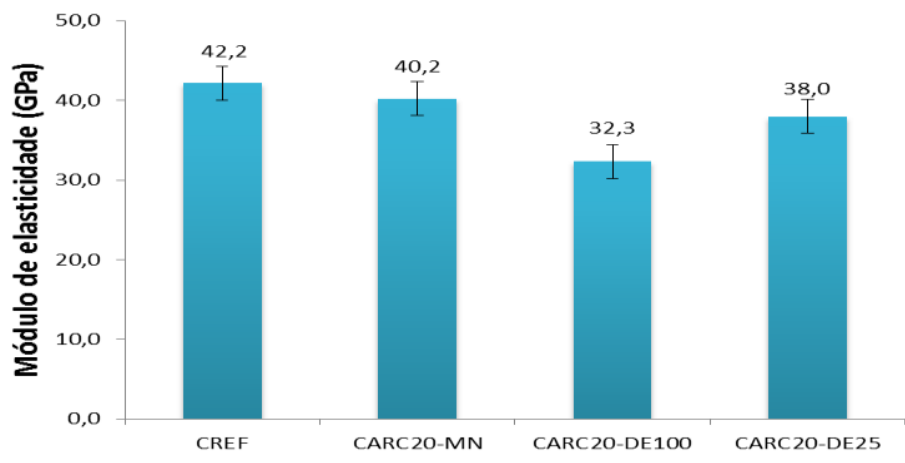

Figura 7: Valores médios do módulo estático de elasticidade dos concretos aos 28 dias. 
De acordo com o teste de Duncan, foi possível verificar que o CREF e CARC20-MN não diferem estatisticamente entre si, pertencendo a um mesmo grupo com valores de módulo de elasticidade mais altos. $\mathrm{O}$ CARC20-DE25 está em um grupo com o nível do módulo de elasticidade intermediário. Já o CARC20DE100 é pertencente ao grupo com o menor nível de valor de módulo de elasticidade, confirmando o efeito prejudicial da utilização de $100 \%$ de cimento Portland na primeira etapa da abordagem de mistura dois estágios nesta propriedade.

Como foi considerada $100 \%$ da água de absorção do ARC nas dosagens, a redução do valor do módulo de elasticidade do CARC20-M-DE100 está associada à dificuldade de absorver totalmente essa água, o que consequentemente aumenta a relação a/c do concreto. Esta redução também foi observada nos demais ensaios de propriedades mecânicas.

\subsection{Análise da durabilidade dos concretos}

Nesta seção serão apresentados os resultados dos ensaios realizados para avaliar os concretos no que se refere a alguns parâmetros de durabilidade, como a absorção de água por imersão, resistividade elétrica, carbonatação acelerada, migração de cloretos no estado não estacionário e o efeito combinado da carbonatação acelerada e migração de cloretos.

\subsubsection{Absorção de água por imersão}

Na Figura 8 estão apresentados os resultados obtidos no ensaio de absorção de água por imersão, o qual fornece ainda o índice de vazios do concreto.

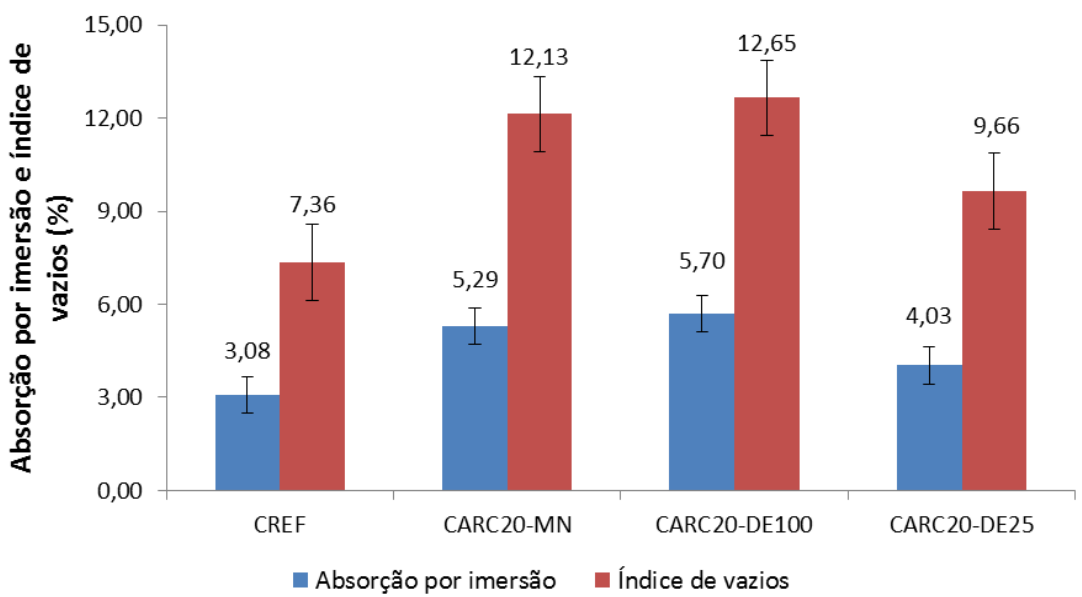

Figura 8: Valores de absorção por imersão e índice de vazios dos concretos aos 91 dias de idade.

Pode-se observar na Figura 8, um aumento de $72 \%$ na absorção de água do concreto utilizando $20 \%$ de ARC (mistura normal) em relação ao concreto referência. Além disso, essa tendência de aumento também foi observada no índice de vazios. O aumento da absorção de água do concreto utilizando agregado reciclado também foi verificado por ALEXANDRIDOU, ANGELOPOULOS e COUTELIERIS [16], quando em seu estudo observou um aumento de $15 \%$ da absorção por imersão e $13 \%$ do volume de poros abertos do concreto com $25 \%$ de ARC em relação ao concreto referência. De acordo com ESTOLANO, FUCALE, VIEIRA FILHO et al. [45], o aumento da absorção de água e do índice de vazios do concreto com ARC é atribuído às próprias características do agregado reciclado, o qual absorve mais água quando comparado ao agregado natural.

A utilização da abordagem de mistura dois estágios com $25 \%$ de cimento Portland favoreceu uma redução de $31 \%$ da absorção de água, quando comparado ao concreto CARC20-MN. Este fato também foi visto por TAM e TAM [24], os quais observaram uma redução da permeabilidade à água de 2,34\% aos 28 dias de idade, da mistura realizada pelo método TSMA (two-stage mixing approach) com $20 \%$ de ARC em comparação à mistura realizada pelo método normal. Por outro lado, a abordagem de mistura dois estágios utilizando $100 \%$ de cimento Portland proporcionou o aumento da absorção de $8 \%$ quando comparado ao CARC20-MN. Os resultados positivos do CARC20-DE25 devem-se a menor proporção de cimento Portland utilizada na primeira etapa, a qual favoreceu a absorção da pasta para o interior do agregado através de sua 
porosidade.

A análise de variância (ANOVA) dos valores de absorção de água por imersão e do índice de vazios confirmou a diferença significativa, indicando Valor- $\mathrm{p}=0,0000$ para ambas as propriedades. Conforme o teste de Duncan, todos os valores são estatisticamente distintos e se encontram em grupos diferentes em relação à absorção de água por imersão. Se tratando do agrupamento de valores do índice de vazios, foi observado que o CREF e CARC20-DE25 diferem estatisticamente de todas as outras composições, ocupando o nível de menor índice de vazios e o intermediário, respectivamente. Já os concretos CARC20-MN e CARC20DE100 são estatisticamente iguais entre si em relação a esta propriedade e ocupam o patamar de maior índice de vazios.

\subsubsection{Resistividade elétrica}

$\mathrm{Na}$ Tabela 6 estão apresentados os dados obtidos nos ensaios de resistividade elétrica (volumétrica e superficial). A resistividade elétrica está relacionada à permeabilidade do concreto a fluidos e a difusividade de íons através da porosidade do material. Quanto maior o valor da resistividade elétrica, melhor é o concreto.

Tabela 6: Valores de resistividade elétrica volumétrica e superficial dos concretos aos 91 dias.

\begin{tabular}{l|l|l}
\hline COMPOSIÇÃO & $\begin{array}{l}\text { RESISTIVIDADE ELÉTRICA } \\
\text { VOLUMÉTRICA }(\mathbf{k} \boldsymbol{\Omega} . \mathbf{c m})\end{array}$ & $\begin{array}{l}\text { RESISTIVIDADE ELÉTRICA } \\
\text { SUPERFICIAL }(\mathbf{k} \boldsymbol{\Omega} . \mathbf{c m})\end{array}$ \\
\hline CREF & 9,33 & 11,60 \\
\hline CARC20-MN & 6,83 & 8,10 \\
\hline CARC20-DE100 & 7,50 & 8,64 \\
\hline CARC20-DE25 & 7,65 & 10,52 \\
\hline
\end{tabular}

De acordo com a Tabela 6, o CREF possui a maior resistividade elétrica (para ambos os métodos), enquanto que o concreto com agregado reciclado com mistura normal (CARC20-MN) apresentou a menor resistividade. Essa tendência de decréscimo da resistividade em concretos com agregados reciclados é atribuída à maior permeabilidade, presença de argamassa residual e a disponibilidade de zona de transições enfraquecidas. Esse comportamento também foi observado por SADATI e KHAYAT [18]. No entanto, a utilização de tratamentos nos agregados reciclados proporcionou melhorias no comportamento dos concretos, sendo notável o aumento da resistividade elétrica, especialmente para o CARC20-DE25.

A partir dos resultados de resistividade elétrica volumétrica, foi realizada a classificação dos concretos quanto ao risco de corrosão e à penetração de íons cloreto, conforme está apresentada na Tabela 7. De acordo com a norma CEB - 192 e o boletim europeu COST 509, todos os concretos foram classificados como risco de corrosão alto, inclusive o CREF. Já em relação à possibilidade de penetração de íons cloreto, foram classificados como moderados, conforme a AASHTO TP119:15.

Tabela 7: Classificação dos concretos quanto ao risco de corrosão e penetração de íons cloreto, para os valores de resistividade elétrica volumétrica.

\begin{tabular}{l|l|l|l}
\hline \multirow{2}{*}{ COMPOSIÇÃo } & $\begin{array}{l}\text { RISCO DE CORRO- } \\
\text { SÃo }\end{array}$ & $\begin{array}{l}\text { RISCO DE CORRO- } \\
\text { SÃo }\end{array}$ & $\begin{array}{l}\text { CLASSIFICAÇÃO } \\
\text { QUANTO A PENE- } \\
\text { TRAÇÃO DE íONS } \\
\text { CLORETO }\end{array}$ \\
\cline { 2 - 4 } & CEB - 192 & COST 509 & AASHTO TP119:15 \\
\hline CREF & Alto & Alto & Moderada \\
\hline CARC20-MN & Alto & Alto & Moderada \\
\hline CARC20-DE100 & Alto & Alto & Moderada \\
\hline CARC20-DE25 & Alto & Alto & Moderada \\
\hline
\end{tabular}

De acordo com as classificações da Tabela 7, os concretos com ARC apresentaram comportamentos semelhantes ao CREF no que se refere à probabilidade de corrosão das armaduras e penetração de íons cloretos. Este fato está associado à proximidade dos valores de resistividade elétrica volumétrica, os quais estão no 
mesmo intervalo de classificação.

Os valores de resistividade elétrica superficial também foram classificados quanto ao risco de corrosão. Na Tabela 8 são apresentadas as classificações dos concretos.

Tabela 8: Classificação dos concretos quanto ao risco de corrosão, para os valores de resistividade elétrica superficial.

\begin{tabular}{l|l|l}
\hline \multirow{2}{*}{ COMPOSIÇÃo } & RISCO DE CORROSÃo & RISCO DE CORROSÃO \\
\cline { 2 - 3 } & CEB -192 & COST 509 \\
\hline CREF & Baixo & Moderado \\
\hline CARC20-MN & Alto & Alto \\
\hline CARC20-DE100 & Alto & Alto \\
\hline CARC20-DE25 & Baixo & Moderado \\
\hline
\end{tabular}

De acordo com a norma CEB - 192 e o boletim europeu COST 509, o CREF e o CARC20-DE25 foram classificados com risco de corrosão baixo e moderado. Já o CARC20-MN e CARC20-DE100 apresentaram risco de corrosão alto. Ou seja, conforme estas classificações, a adoção da abordagem de mistura dois estágios com 25\% de cimento Portland tende a proporcionar melhorias no concreto com ARC, reduzindo o risco de corrosão das armaduras.

Analisando estatisticamente estes valores, a ANOVA indicou Valor-p de 0,0000 e 0,0168 para a resistividade elétrica volumétrica e superficial, respectivamente. Sendo assim, o teor de substituição de $20 \%$ do agregado graúdo natural por agregado reciclado (mistura normal e dois estágios com 25 e $100 \%$ de cimento Portland) influenciou significativamente na resistividade elétrica do concreto.

Para melhor compreender os resultados, foi realizado o teste de Duncan buscando agrupar as composições que não diferem estatisticamente entre si. Analisando o agrupamento dos valores de resistividade elétrica volumétrica, foi observado que os concretos estão divididos em três grupos distintos. O CREF compõe o grupo que possui um nível de resistividade elétrica volumétrica mais alto. Os concretos produzidos com $20 \%$ de ARC através da abordagem de mistura dois estágios com 25 e $100 \%$ de cimento Portland, pertencem ao mesmo grupo de resistividade elétrica volumétrica, não diferindo estatisticamente entre si. Já o CARC20-MN está inserido no grupo que possui o menor nível de resistividade elétrica volumétrica. Se tratando da resistividade elétrica superficial, os concretos estão divididos em três grupos conforme o patamar de valores. $\mathrm{O}$ grupo 1 engloba os concretos com maiores valores de resistividade, sendo composto pelo CREF e o CARC20-DE25, observando que este último possui valores intermediários entre o grupo 1 e o grupo 2. Ou seja, quando se realiza a mistura dois estágios com $25 \%$ de cimento Portland, na perspectiva de resistividade elétrica superficial, o concreto tende a se igualar à referência. $\mathrm{O}$ grupo 2 além de ser composto pelo CAR20DE25 também abrange o CAR20-DE100. Já o grupo 3, o que possui menores valores de resistividade, é composto também pelo CAR20-DE100 e pelo CARC20-MN. Com isso, é notório que a utilização de tratamentos nos ARC, por meio da abordagem de mistura dois estágios, proporciona melhorias na qualidade desses agregados e consequentemente nos concretos produzidos com eles.

\subsubsection{Carbonatação acelerada}

Na Figura 9 estão apresentados os resultados obtidos nos ensaios de carbonatação acelerada aos 56 e 70 dias de exposição. Este ensaio é importante para avaliar como o concreto armado se comporta em ambientes com alta concentração de $\mathrm{CO}_{2}$, considerando que nestes lugares a despassivação das armaduras por carbonatação acontecem com maior facilidade.

Os resultados apresentados na Figura 9 equivalem à média de 28 leituras realizadas nos corpos de prova que foram submetidos à exposição de $\mathrm{CO}_{2}$. Foi possível observar que o $\mathrm{CARC20}$-MN apresentou um aumento de 30,7 \% na frente de carbonatação em relação ao concreto referência (CREF) aos 70 dias, o que corrobora com BRAVO, DE BRITO, PONTES et al. [17], que afirmam que os concretos com agregados reciclados possuem menor resistência à carbonatação.

A adoção da mistura dois estágios com $100 \%$ de cimento Portland causou um aumento da frente de carbonatação de $45 \%$ quando comparado ao CARC20-MN aos 70 dias, o que indica que piorou o comportamento do concreto no que se refere à resistência à carbonatação. $\mathrm{O}$ comportamento negativo do CARCDE100 deve-se à dificuldade de absorção da pasta para o interior do agregado devido ao maior teor de cimento Portland utilizado no primeiro estágio. Além disso, como foi considerada a água de absorção do ARC para a dosagem, também foi gerada uma matriz mais fraca. 


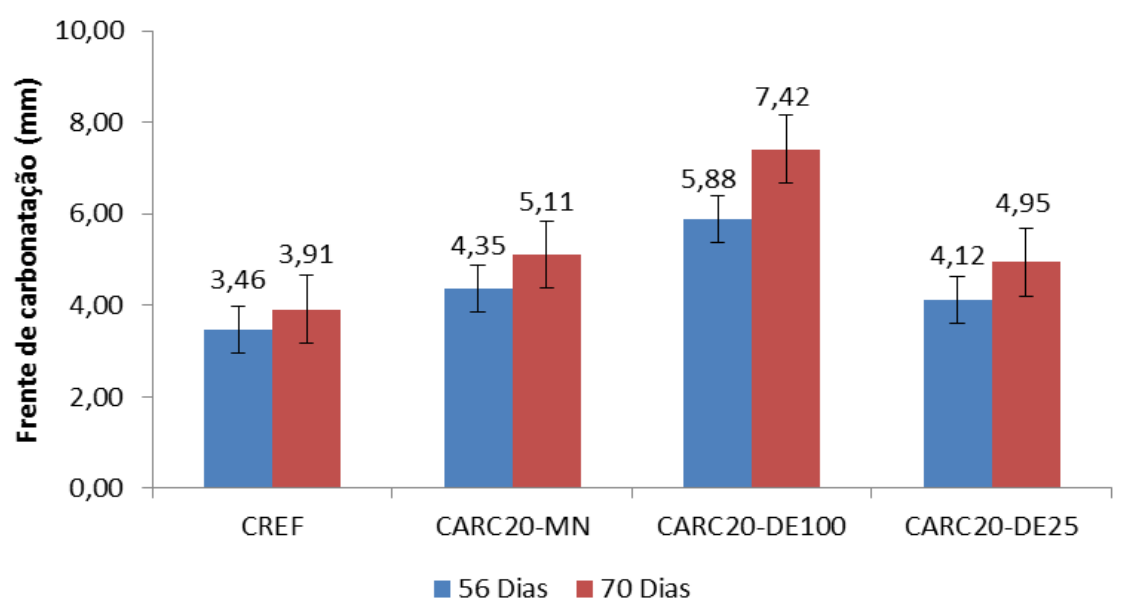

Figura 9: Valores médios de carbonatação acelerada dos concretos após 56 e 70 dias de exposição.

A abordagem de mistura dois estágios com $25 \%$ de cimento Portland (CARC20-DE25) tendeu a diminuir a frente de carbonatação em 3,2 \% quando comparado ao concreto com agregado reciclado com mistura normal (CARC20-MN), aos 70 dias. O comportamento positivo do CARC20-DE25 é atribuído à facilidade de penetração da pasta de pré-molhagem para o interior do ARC por meio de sua porosidade, o que ocasionou a densificação da microestrutura e a redução do índice de vazios, conforme já apresentado.

A análise de variância (ANOVA) indicou que a utilização de agregado reciclado (mistura normal e dois estágios) não influenciou significativamente no que se refere à frente de carbonatação, considerando que o Valor-p foi equivalente a 0,4418 e 0,1957 para 56 e 70 dias, respectivamente.

\subsubsection{Migração de cloretos no estado não estacionário}

A migração de cloretos no estado não estacionário foi realizada buscando obter os coeficientes de difusão, sendo este dado bastante representativo no que se refere ao real mecanismo de transporte de cloretos no concreto. É válido destacar que quanto maior o valor do coeficiente de difusão de cloretos, pior é o desempenho do concreto. Na Figura 10 estão apresentados os resultados obtidos nos ensaios, sendo realizados aos 28 e 91 dias de idade.

Foi observado que em relação ao CREF, o CARC20-MN apresentou um aumento de 58,7 \% e $175,7 \%$ no coeficiente de difusão de cloretos aos 28 e 91 dias, respectivamente. Estes resultados condizem com o estudo de BRAVO, DE BRITO, PONTES et al. [17], os quais mencionam que a utilização de agregados reciclados no concreto implica em um aumento do coeficiente de difusão de cloretos em relação ao concreto convencional.

Com a utilização da abordagem de mistura dois estágios com $25 \%$ de cimento Portland (CARC20DE25) foi notória uma diminuição desse coeficiente em relação ao CARC20-MN, principalmente aos 91 dias, no qual a redução foi equivalente a 92,4 \%. Esta redução do coeficiente de difusão de cloretos com a utilização de tratamentos nos ARC também foi verificada por TAM e TAM [24], os quais observaram uma redução de 22,78 \% e 0,70 \% da TSMA (two-stage mixing approach) em relação ao método de mistura normal, aos 28 e 98 dias, respectivamente.

A mistura dois estágios com $100 \%$ de cimento Portland (CARC20-DE100) apresentou um aumento de $8,7 \%$ e 5,9 \% do coeficiente de difusão de cloretos aos 28 e 91 dias, respectivamente, em relação ao CARC20-MN. É possível observar ainda que o coeficiente de difusão de cloretos aos 91 dias de todas as composições são menores do que o coeficiente de 28 dias. Este comportamento está associado ao aumento dos produtos de hidratação do cimento que provavelmente refinou os poros e dificultou a penetração de cloretos. 


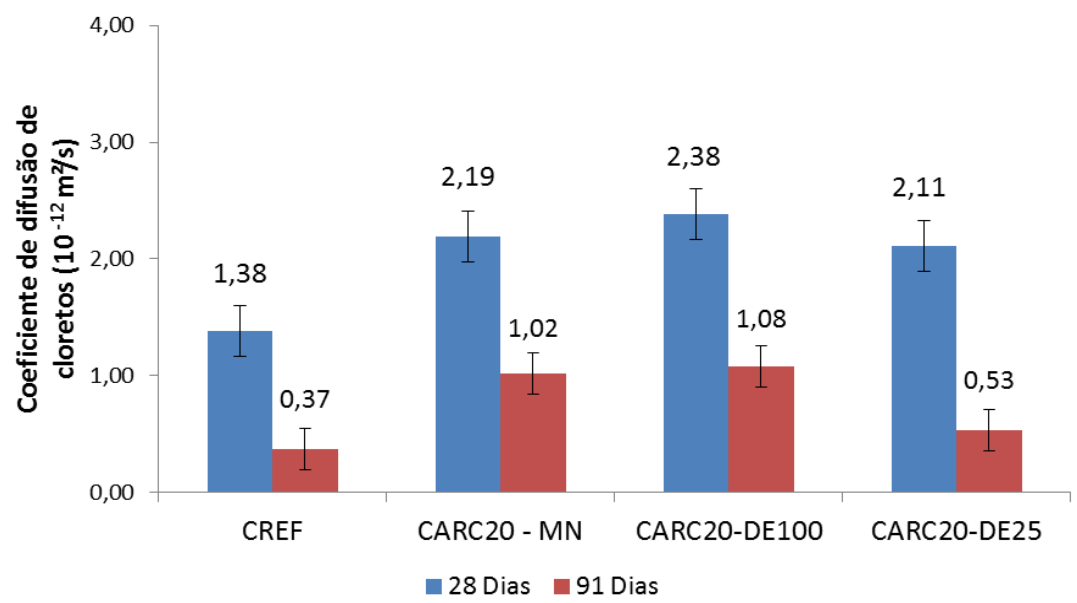

Figura 10: Valores médios do coeficiente de difusão de cloretos dos concretos aos 28 e 91 dias.

Ao realizar a análise de variância (ANOVA) para os dados em questão, foi indicado que a substituição de $20 \%$ de ARC no concreto (mistura normal e dois estágios) não exerceu efeito significativo, considerando que o Valor-p foi equivalente a 0,1421 e 0,1019 aos 28 e 91 dias, respectivamente. No entanto, mesmo não havendo diferença significativa, o tratamento com $25 \%$ de cimento Portland (CARC20-DE25) foi eficiente em relação ao método de mistura normal (CARC20-MN), principalmente aos 91 dias.

\subsubsection{Efeito combinado da carbonatação acelerada e migração de cloretos no estado não estacionário}

Considerando que no cotidiano o que geralmente ocorre é a combinação da ação de agentes externos, como por exemplo, a ação de cloretos e dióxido de carbono simultaneamente no concreto, foi realizado o estudo do efeito combinado destes dois agentes.

Na Figura 11 estão apresentados os resultados do coeficiente de difusão de cloretos isoladamente (sem carbonatação) e os resultados do coeficiente de difusão de cloretos dos concretos após a carbonatação acelerada. Apesar dos resultados do coeficiente de difusão de cloretos já terem sido mostrados anteriormente, foram apresentados novamente para comparar com os resultados do efeito combinado.

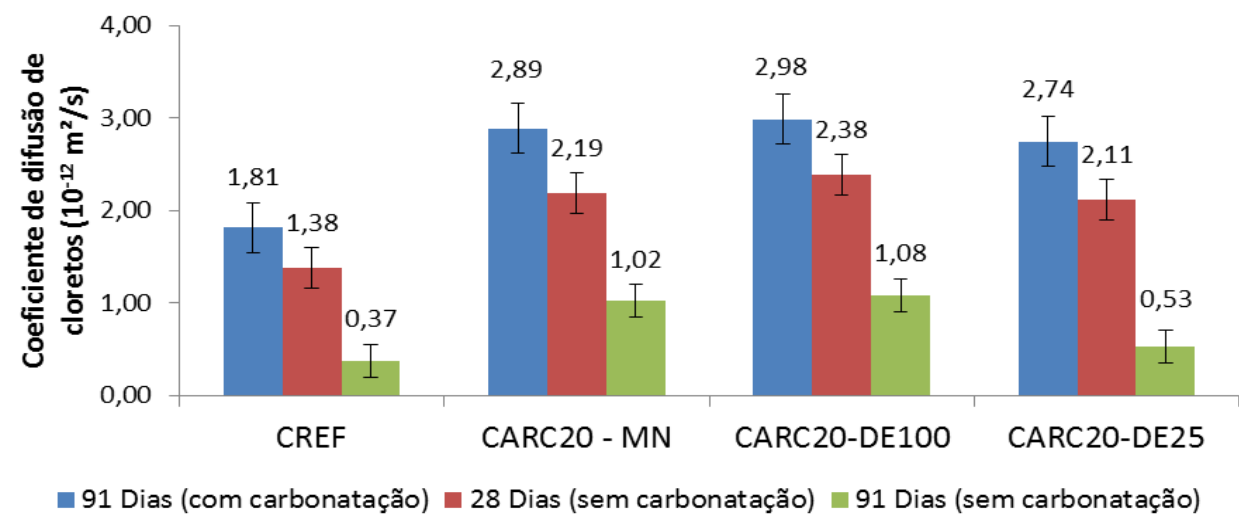

Figura 11: Valores médios do coeficiente de difusão de cloretos dos concretos aos 28 e 91 dias (com e sem carbonatação).

É importante destacar que os concretos não carbonatados que sofreram migração de cloretos aos 91 dias de idade, ficaram em cura úmida por 91 dias até a realização do ensaio. Já os concretos carbonatados, permaneceram em cura úmida por 28 dias, pré-condicionamento por 7 dias e foram carbonatados por 56 dias, sendo assim a migração de cloretos foi realizada aos 91 dias de idade.

Pode-se observar que os concretos com carbonatação apresentaram coeficientes de difusão de cloretos maiores que os concretos sem carbonatação aos 91 dias, indicando que a carbonatação influenciou mais do 
que o tempo de cura nesse resultado. De acordo BOLINA [46], este fato deve-se à redução do pH dos concretos, ocasionado pela carbonatação, que desestabiliza os cloretos combinados e disponibiliza maior quantidade de cloretos livres para a solução porosa dos concretos, aumentando, desta forma, o processo de difusão para o interior da estrutura, elevando o coeficiente de difusão de cloretos.

Em relação aos concretos com 91 dias sem carbonatação, os concretos carbonatados apresentaram aumento no coeficiente de difusão de cloretos de $389,2 \%, 183,3 \%, 175,9 \%$ e $416,9 \%$ para CREF, CARC20-MN, CARC20-DE100 e CARC20-DE25, respectivamente.

É notório ainda que todos os concretos (com carbonatação) aos 91 dias também superaram o coeficiente de difusão de cloretos dos concretos (sem carbonatação) aos 28 dias, confirmando que a carbonatação contribuiu mais com a penetração de cloretos do que a idade dos concretos.

A análise de variância (ANOVA) indicou Valor-p= 0,0042 , o que aponta que os concretos apresentaram diferença significativa entre si, em relação à ação combinada de carbonatação e migração de cloretos. Com isso, foi realizado o teste de Duncan buscando agrupar as composições que não diferem estatisticamente entre si, em relação ao coeficiente de difusão de cloretos.

De acordo com o teste de Duncan, as composições foram divididos em dois grupos de acordo com o nível do coeficiente de difusão de cloretos. O grupo 1 é composto pelo concreto referência (CREF), o qual apresentou o menor coeficiente de difusão de cloretos. Já o grupo 2 envolveu o CARC20-DE25, CARC20MN e CARC20-DE100, ou seja, todos os concretos que utilizaram agregado reciclado, os quais apresentaram coeficiente de difusão de cloretos em torno de 51 a $65 \%$ maiores do que o CREF.

\section{CONCLUSÕES}

A partir dos resultados experimentais deste estudo, ficou evidente que a utilização de $20 \%$ de agregados de resíduo de concreto na produção de um novo concreto produz efeitos negativos nas propriedades deste quando comparado ao convencional. Este fato deve-se principalmente à argamassa antiga aderida ao agregado reciclado, que o torna mais poroso, permeável e menos denso quando comparado ao agregado natural.

No entanto, ao realizar o tratamento nos ARC através da abordagem de mistura dois estágios com $25 \%$ de cimento Portland, foi notável a melhoria do concreto quando comparado à abordagem de mistura normal. Esta melhoria ocorreu devido à etapa de pré-molhagem ( $1^{\circ}$ estágio ajudar a aliviar o problema, uma vez que a pasta de cimento penetra nos poros do agregado reciclado e ainda gera uma película envoltória, o que consequentemente reduz a porosidade destes agregados.

O concreto produzido por meio da abordagem de mistura dois estágios com $100 \%$ de cimento Portland apresentou resultados insatisfatórios quando comparado ao produzido pelo método de mistura normal. $\mathrm{O}$ efeito negativo foi associado à maior consistência da pasta de cimento ( $1^{\circ}$ estágio), a qual dificultou a absorção total da água de compensação por parte dos agregados reciclados, o que consequentemente aumentou a relação a/c do concreto.

A adoção da abordagem de mistura dois estágios com $25 \%$ de cimento Portland mostrou-se como uma alternativa viável para proporcionar melhorias nos agregados de resíduo de concreto, considerando que além de resultar em um concreto com boas características de propriedades mecânicas e durabilidade, viabiliza a utilização de agregados reciclados e não gera custo adicional no processo de produção do concreto.

\section{AGRADECIMENTOS}

Os agradecimentos vão direcionados ao Programa de Pós-Graduação em Estruturas e Construção Civil (PECC) da Universidade de Brasília, a CAPES, a FAP-DF (Processo 0193.001700/2017) e a BASF pelo apoio na elaboração deste estudo.

\section{BIBLIOGRAFIA}

[1] GUO, H., SHI, C., GUAN, X., et al. "Durability of recycled aggregate concrete - A review", Cement and Concrete Composites, v. 89, p. 251-259, 2018.

[2] ASSOCIAÇÃO BRASILEIRA DE NORMAS TÉCNICAS (ABNT). NBR 15116:2004 - Agregados reciclados de resíduos sólidos da construção civil - Utilização em pavimentação e preparo de concreto sem função estrutural - Requisitos. Rio de Janeiro, 2004.

[3] ISMAIL, S., RAMLI, M. "Mechanical strength and drying shrinkage properties of concrete containing treated coarse recycled concrete aggregates", Construction and Building Materials, v. 68, pp. 726-739, 2014.

[4] PADMINI, A. K., RAMAMURTHY, K., MATHEWS, M. S. "Influence of parent concrete on the 
properties of recycled aggregate concrete", Construction and Building Materials, v. 23, n. 2, pp. 829-836, 2009.

[5] KWAN, W. H., RAMLI, M., KAM, K. J., et al. "Influence of the amount of recycled coarse aggregate in concrete design and durability properties", Construction and Building Materials, v. 26, n. 1, pp. 565-573, 2012.

[6] DIMITRIOU, G., SAVVA, P., PETROU, M. F. "Enhancing mechanical and durability properties of recycled aggregate concrete", Construction and Building Materials, v. 158, pp. 228-235, 2018.

[7] POON, C. S., SHUI, Z. H., LAM, L. "Effect of microstructure of ITZ on compressive strength of concrete prepared with recycled aggregates", Construction and Building Materials, v. 18, n. 6, pp. 461-468, 2004.

[8] TABSH, S.W., ABDELFATAH, A. S. "Influence of recycled concrete aggregates on strength properties of concrete", Construction and Building Materials, v. 23, pp. 1163-1167, 2009.

[9] ETXEBERRIA, M., VÁZQUEZ, E., MARÍ, A., et al. "Influence of amount of recycled coarse aggregates and production process on properties of recycled aggregate concrete", Cement and Concrete Research, v. 37, n. 5, pp. 735-742, 2007.

[10] THOMAS, C., SETIÉN, J., POLANCO, J. A., et al. "Durability of recycled aggregate concrete", Construction and Building Materials, v. 40, pp. 1054-1065, 2013.

[11] XIAO, J., LI, W., FAN, Y., et al. "An overview of study on recycled aggregate concrete in China (1996-2011)", Construction and Building Materials, v. 31, pp. 364-383, 2012.

[12] CHEN, B. "Basic mechanical properties and microstructural analysis of recycled concrete", Journal Wuhan University of Technology, Materials Science Edition, v. 28, n. 1, pp. 104-109, 2013.

[13] KOU, S. C., POON, C. S., CHAN, D. "Influence of Fly Ash as Cement Replacement on the Properties of Recycled Aggregate Concrete", Journal of Materials in Civil Engineering, v. 19, n. 9, pp. 709-717, 2007.

[14] XIAO, J.Z., LAN, Y. "Investigation on the tensile behavior of recycled aggregate concrete", Chinese J Build Mater, v. 8, n. 2, pp. 154 - 158, 2006.

[15] BHASYA, V., BHARATKUMAR, B. H. "Mechanical and Durability Properties of Concrete Produced with Treated Recycled Concrete Aggregate”, ACI Materials Journal, n. 115, pp. 209-218, 2018.

[16] AlEXANDridou, C., ANGElOPOUlOS, G. N., COUTELIERIS, F. A. "Mechanical and durability performance of concrete produced with recycled aggregates from Greek construction and demolition waste plants", Journal of Cleaner Production, v. 176, pp. 745-757, 2018.

[17] BRAVO, M., DE BRITO, J., PONTES, J., et al. "Durability performance of concrete with recycled aggregates from construction and demolition waste plants", Construction and Building Materials, v. 77, pp. 357-369, 2015

[18] SADATI, S., KHAYAT, K. H. "Can concrete containing high-volume recycled concrete aggregate be durable?”, ACI Materials Journal, v. 115, n. 3, pp. 471-480, 2018.

[19] TAM, V. W. Y., GAO X. F., TAM, C. M. "Microstructural analysis of recycled aggregate concrete produced from two-stage mixing approach", Cement and Concrete Research, v. 35, pp. 1195-1203, 2005.

[20] TAM, V. W. Y., TAM, C. M. "Diversifying two-stage mixing approach (TSMA) for recycled aggregate concrete: TSMAs and TSMAsc”, Construction and Building Materials, v. 22, n. 10, pp. 2068-2077, 2008.

[21] ZHIHUI, Z., SHOUDE, W., LINGCHAO, L., et al. "Evaluation of pre-coated recycled aggregate for concrete and mortar", Construction and Building Materials, v. 43, pp. 191-196, 2013.

[22] GÜNEYISI, E., GESOGLU, M., ALGIN, Z., et al., "Effect of surface treatment methods on the properties of self-compacting concrete with recycled aggregates", Construction and Building Materials, v. 64, pp. 172-183, 2014.

[23] KATZ, A. "Treatments for the Improvement of Recycled Aggregate", Journal of Materials in Civil Engineering, v. 16, n. 6, pp. 597-603, 2004.

[24] TAM, V. W. Y., TAM, C. M. "Assessment of durability of recycled aggregate concrete produced by two-stage mixing approach”, Journal of Materials Science, v. 42, n. 10, pp. 3592-3602, 2007.

[25] HELENE, P., TERZIAN, P. Manual de dosagem e controle do concreto, São Paulo, PINI. SENAI., 1992. 
[26] LEITE, M.B. “Avaliação de propriedades mecânicas de concretos produzidos com agregados reciclados de resíduos de construção e demolição", Tese de D.Sc., Departamento de Engenharia - Universidade Federal do Rio Grande do Sul, Porto Alegre, 2001.

[27] ASSOCIAÇÃO BRASILEIRA DE NORMAS TÉCNICAS (ABNT). NBR 5738:2015 - Concreto - Procedimento para moldagem e cura de corpos de prova. Rio de Janeiro, 2015.

[28] _. NBR NM 67:1998 - Concreto - Determinação da consistência pelo abatimento do tronco de cone. Rio de Janeiro, 1998.

[29] Janeiro, 2018.

NBR 5739:2018 - Concreto - Ensaios de compressão de corpos de prova cilíndricos. Rio de

[30]

NBR 7222:2011 - Argamassa e concreto - Determinação da resistência à tração por compressão diametral de corpos-de-prova cilíndricos. Rio de Janeiro, 2011.

[31] NBR 8522:2008 - Concreto - Determinação do módulo estático de elasticidade à compressão. Rio de Janeiro, 2008.

[32] __ NBR 9778:2005 - Argamassa e concreto endurecidos - Determinação da absorção de água, índice de vazios e massa específica. Rio de Janeiro, 2005.

[33] AMERICAN ASSOCIATION OF STAT HIGHWAY AND TRANSPORTATION OFFICIALS. TP119-15: Electrical Resistivity of a concrete cylinder tested in a uniaxial resistance test. Estados Unidos, 2015.

[34] AMERICAN SOCIETY FOR TESTING AND MATERIALS - ASTM. G57:2012 - Standard Test Method for Field Measurement of Soil Resistivity Using the Wenner Four-Electrode Method., 2012.

[35] ISO. ISO 1920-12:2015 - Testing of concrete. Part 12 - Determination of the carbonation resistance of concrete - Accelerated carbonation method. Geneva, Switzerland, 2015.

[36] NT BUILD. 492:2011 - Chloride migration coefficient from non-steady-state migration experiments. 2011.

[37] ASSOCIAÇÃO BRASILEIRA DE NORMAS TÉCNICAS (ABNT). NBR 16605:2017 - Cimento Portland e outros materiais em pó - Determinação da massa específica. Rio de Janeiro, 2017.

[38] . NBR 11579:2012 - Cimento Portland - Determinação do índice de finura por meio da peneira $75 \mu \mathrm{m}$ (n 200). Rio de Janeiro, 2012.

[39] _. NBR NM 65:2003 - Cimento Portland - Determinação do tempo de pega. Rio de Janeiro, 2003.

[40] ro, 2003

NBR NM 248:2003 - Agregados - Determinação da composição granulométrica. Rio de Janei-

[41] NBR NM 52:2009 - Agregado miúdo - Determinação de massa específica e massa específica aparente. Rio de Janeiro, 2009.

[42] NBR NM 45:2006 - Agregados - Determinação da massa unitária e do volume de vazios. Rio de Janeiro, 2006

[43]

NBR NM 53:2009 - Agregado graúdo - Determinação de massa específica, massa específica aparente e absorção de água. Rio de Janeiro, 2009.

[44] __ NBR 8953:2015 - Concreto para fins estruturais - Classificação pela massa específica, por grupos de resistência e consistência. Rio de Janeiro, 2015.

[45] ESTOLANO, V.; FUCALE, S.; VIEIRA FILHO, J. O., et al. "Avaliação dos módulos de elasticidade estático e dinâmico de concretos produzidos com agregados reciclados oriundos de resíduos de préfabricados de concreto", Revista Matéria, v.23, n.1, 2018.

[46] BOLINA, C. DE C. "Inibidores de corrosão: Avaliação do desempenho frente a corrosão do aço induzida por carbonatação e cloretos”, Dissertação de M.Sc., Universidade Federal de Goiânia, 2008.

\section{ORCID}

Carla Mabel Medeiros de Albuquerque e Silva https://orcid.org/0000-0001-7572-2145 Valdirene Maria Silva Capuzzo

https://orcid.org/0000-0001-6923-7565 